\title{
Experimental investigation on the influence of system pressure on resulting spray quality and jet breakup applying pressure adapted twin-fluid nozzles
}

\author{
Simon Wachter ${ }^{\mathrm{a}, *}$, Tobias Jakobs ${ }^{\mathrm{a}}$, Thomas Kolb ${ }^{\mathrm{a}, \mathrm{b}}$ \\ a Institute of Technical Chemistry, Gasification Technology, Karlsruhe Institute of Technology, Eggenstein-Leopoldshafen, BW 76344, Germany \\ ${ }^{\mathrm{b}}$ Engler-Bunte-Institute, Fuel Technology, Karlsruhe Institute of Technology, Karlsruhe, BW 76131, Germany
}

Keywords:

Twin-fluid atomization

Viscosity

System pressure

Nozzle scaling

\begin{abstract}
A B S T R A C T
The present work aims for the isolated investigation of the influence of system pressure on spray quality of twin-fluid atomizers. An approach of pressure adapted nozzles was applied, allowing for constant mass flows, gas-to-liquid ratio as well as fluid velocities at the nozzle orifice independent of system pressure. Two Newtonian liquids featuring viscosities of 1 and $100 \mathrm{mPa} \cdot \mathrm{s}$ were used, varying the system pressure from 1 to 16 bar for gas velocities of 60,80 and $100 \mathrm{~m} \cdot \mathrm{s}^{-1}$. A phase doppler analyzer was applied for measurement of resulting drop size and velocity. Primary breakup morphology was detected by a high-speed camera. Two regions with different dependencies of spray quality on system pressure were identified. Applying pressure adapted nozzles while increasing system pressure, first results in a decrease of droplet size followed by an increase. A maximum of the dynamic pressure of the gas phase was determined at minimum droplet size, which is explained based on the theory of a free jet. The observations are underlined by images of the high-speed camera. Here, a change in breakup morphology from fiber type to a mixture of fiber type and non-axisymmetric Rayleigh type breakup at high system pressure was observed.
\end{abstract}

\section{Introduction}

Although spraying processes are often used in industrial applications, the influence of process conditions and liquid properties is not yet fully understood. Especially knowledge of the twin-fluid atomization process at high system pressure relevant for energy conversion systems is scarce. Investigations on the liquid disintegration process in gas turbines (Lefebvre, 1998) and rocket propulsion (Haidn and Habiballah, 2003) at high system pressure were carried out, with varying nozzle geometries and under different process conditions. Mostly, low viscosity liquids $\left(\eta_{\text {liq }}<50 \mathrm{mPa} \cdot \mathrm{s}\right)$ were used, without consideration of high viscosity fuels. Typically, high viscosity liquids or suspension fuels featuring viscosities up to $1000 \mathrm{mPa}$. s and complex rheological behaviour (e.g., nonNewtonian flow, viscoelasticity) are applied in entrained flow gasification systems (EFG), which are operated at elevated system pressure (absolute pressure up to 80 bar) (Fleck et al., 2018). Oxygen is used as gasification agent and at the same time serves as atomization agent, i.e. stoichiometry and gas-to-liquid mass flow ratio

\footnotetext{
* Corresponding author.

E-mail address: simon.wachter@kit.edu (S. Wachter).
}

(GLR) are directly coupled. Based on the required low stoichiometry of the gasification reaction, the spray nozzle has to be operated at $G L R \leq 1$. For optimization of the atomization process at conditions relevant for an EFG or for design and scale-up of burner nozzles applied in an EFG, it is an essential research objective to gain fundamental knowledge concerning the atomization behaviour of high viscosity liquids at high process pressure (Jakobs et al., 2012).

Theoretical and experimental investigations regarding the atomization of low viscosity liquids using twin-fluid atomizers at atmospheric system pressure are common (Marmottant and Villermaux, 2004). An overview comparing different twin-fluid nozzle concepts is given by Hede et al. (2008). Chigier and Faragó (1992) used a high-speed camera to investigate the primary breakup of a water jet applying twin-fluid nozzles. A regime classification for liquid breakup morphology was proposed for different nozzle geometries, using $R e_{l i q}$ and We aero, according to Eqs. (1) and (2) to describe process conditions:

$\operatorname{Re}_{\text {liq }}=\frac{D_{\text {liq }} \cdot v_{\text {liq }} \cdot \rho_{\text {liq }}}{\eta_{\text {liq }}}$

$W e_{\text {aero }}=\frac{\left(v_{\text {gas }}-v_{\text {liq }}\right)^{2} \cdot \rho_{\text {gas }} \cdot D_{\text {liq }}}{\sigma}$ 
Table 1

Summary of investigations applying external mixing twin-fluid nozzles with $\eta_{\text {liq }}>50 \mathrm{mPa} \cdot \mathrm{s}$ at $p_{\text {sys }}=$ 1 bar.

\begin{tabular}{lllll}
\hline Author (year) & Measurement & GLR & $\eta_{\text {liq }}$ in $\mathrm{mPa} \cdot \mathrm{s}$ & (I) $D_{a b} \sim \eta_{\text {liq }}^{X}$ \\
\hline Lorenzetto and Lefebvre (1977) & LDS & $2-3.67$ & $1.3-76$ & $(I) D_{32} \sim \eta_{\text {liq }}^{1}$ \\
Jasuja (1982) & LDS & $2-12$ & $1.3-74.9$ & $(I) D_{32} \sim \eta_{\text {liq }}^{0.8}$ \\
Walzel (1990) & LDS & N/A & $1-100$ & $(I) D_{32} \sim \eta_{\text {liq }}^{1}$ \\
Aliseda et al. (2008) & PDA, HSC & 7.69 & $1-77.6$ & $(I) D_{32} \sim \eta_{\text {liq }}^{0.67}$ \\
Li et al. (2009) & SZ, HSC & $1-2.5$ & $1-805$ & N/A \\
Sänger (2018) & PDA, HSC & $0.4-13.8$ & $100-400$ & M: $(I) D_{32} \sim \eta_{\text {liq }}^{0.47}$ \\
& & & & F: $(I) D_{32} \sim \eta_{\text {liq }}^{0.15}$ \\
\hline
\end{tabular}

with liquid jet diameter $\left(D_{\text {liq }}\right)$, velocity $(v)$, density $(\rho)$, dynamic viscosity $\left(\eta_{\text {liq }}\right)$, and surface tension $(\sigma)$ as relevant process parameters. The subscripts gas and liq denote gas and liquid phase, respectively. For low $W e_{\text {aero }}$, the primary atomization is characterized by the so-called Rayleigh type regime, where the liquid jet disintegrates into large droplets on the centerline of the spray. With increasing $W e_{a e r o}$, the membrane type breakup is reached, where gas-filled membranes near the nozzle orifice can be detected. These membranes break into tiny droplets at the thinnest position, whereas the accumulated rim disintegrates according to Rayleigh-Plateau-instabilities. At high $W e_{a e r o}$, the fiber type regime leads to a complete disintegration of the liquid jet into fibers near the nozzle orifice. These ligaments typically disintegrate into small droplets according to the Rayleigh-Plateau-instability. The fiber type regime is divided into the submodes pulsating and superpulsating; the latter is characterized by a fluctuation of droplet number density in the spray. Lasheras and Hopfinger (2000) included the effect of dynamic pressure ratio of gas and liquid phase for the characterization of the fiber type breakup.

The effect of liquid viscosity on primary jet breakup of suspensions applying twin-fluid nozzles was investigated by Zhao et al. (2012). The authors used the Ohnesorge number, see Eq. (3), to expand the previous regime classification towards viscosity-effects of liquid jets. As a comparison of their work with coal-water slurries, the liquid breakup morphology was described by $O h$ and $W e_{a e r o}$, classifying the regimes into Rayleigh type, fiber type, and atomization.

$O h=\frac{\eta_{\text {liq }}}{\sqrt{\rho_{\text {liq }} \cdot \sigma \cdot D_{\text {liq }}}}$

There is a large number of publications that focus on the drop size distribution, whereby most investigations were conducted for low viscosity liquids $\left(\eta_{\text {liq }}<50 \mathrm{mPa} \cdot \mathrm{s}\right)$ and at atmospheric system pressure. Commonly scarce are investigations on the influence of liquid viscosity and system pressure on the atomization. A summary of investigations performed with external mixing twin-fluid nozzles applying high viscosity liquids $\left(\eta_{\text {liq }}>50 \mathrm{mPa} \cdot \mathrm{s}\right)$ at atmospheric system pressure is given in Table 1 .

Lorenzetto and Lefebvre (1977) and Jasuja (1982) investigated the atomization of heavy crude oil with viscosities up to $\eta_{\text {liq }}=$ $76 \mathrm{mPa} \cdot \mathrm{s}$ for gas turbines and combustors. With decreasing gas velocity as well as increasing dynamic viscosity, an increasing drop size was detected with a laser diffraction system (LDS). First investigations on model fuels like mixtures of glycerol/water with $1<\eta_{\text {liq }}<100 \mathrm{mPa} \cdot \mathrm{s}$ were carried out by Walzel (1990), deducing a correlation for drop size estimation based on an energy balance, which shows a linear dependency of the integral Sauter mean diameter on dynamic viscosity. This was in good agreement with the work of Lorenzetto and Lefebvre (1977) and Jasuja (1982). GLR was not given by Walzel. Aliseda et al. (2008) first used a high-speed camera (HSC) visualizing the jet breakup and a phase doppler analyzer (PDA) system for measurements of drop size and velocity applying viscous liquids with up to $\eta_{\text {liq }}=78 \mathrm{mPa} \cdot \mathrm{s}$. The comparison of liquids with different viscosities showed damping effects on the formation of liquid jet instabilities with increased viscosity, resulting in larger droplet sizes. Further investigations applying high viscosity liquids were performed by Li et al. (2009). The authors used liquids with a dynamic viscosity up to $\eta_{l i q}=805 \mathrm{mPa} \cdot \mathrm{s}$ applying a shadowsizer (SZ) for local droplet size measurement and a HSC for visualization of the primary breakup. A negligible effect of dynamic viscosity between $\eta_{\text {liq }}=147 \mathrm{mPa} \cdot \mathrm{s}$ on droplet size was detected, whereas for a liquid viscosity of $\eta_{\text {liq }}=805 \mathrm{mPa} \cdot \mathrm{s}$ no jet disintegration occurred anymore. Sänger (2018) applied different liquids with viscosities up to $\eta_{\text {liq }}=400 \mathrm{mPa}$. s. A dependency of droplet size on primary breakup morphologies, like membrane type (M) and fiber type (F) was reported. Summing up, the previous investigations showed that increasing dynamic viscosity dampens the instabilities relevant for jet breakup, resulting in increased primary jet length and droplet size. Detailed experiments on the external twin-fluid atomization of high viscosity liquids $\left(\eta_{\text {liq }}>50 \mathrm{mPa} \cdot \mathrm{s}\right)$ at pressures above ambient are even more scarce. An overview is given in Table 2.

One of the first studies on the atomization of low viscosity liquids applying a twin-fluid nozzle was carried out by Rizkalla and Lefebvre (1975), applying a prefilming atomizer. A laser diffraction system was used for measurement of drop sizes, varying the system pressure between $p_{\text {sys }}=1-8.5$ bar. System pressure $p_{\text {sys }}$ stands in the following for the ambient pressure in the atomization chamber. A pressurized pipe with an internal nozzle enabling constant liquid mass flow and constant gas velocity $v_{\text {gas }}$ defined at the nozzle orifice was used. A decrease of drop size with increasing pressure was detected. The atomization of viscous liquids $\left(\eta_{\text {liq }}<75 \mathrm{mPa} \cdot \mathrm{s}\right)$ at pressure conditions up to $p_{\text {sys }}=14.2 \mathrm{bar}$, using external mixing twin-fluid nozzles with a swirling gas flow, was performed by Jasuja (1982). For different system pressures, the GLR and gas velocity at the nozzle orifice were set to be constant, while the liquid mass flow was adapted. The authors report that increasing system pressure leads to smaller Sauter mean diameters $\left(D_{32}\right)$. With increasing liquid viscosity, this effect decreases. Elkotb et al. (1982) used a coated glass plate (CGP) and optical measurement techniques for detection of droplet sizes from the atomization of low viscosity liquids at elevated pressures $p_{\text {sys }}=$ 18 bar. Due to simultaneous changes in system pressure and gas velocity, specific influences on atomization cannot be separated. Investigations on the influence of liquid physical properties and varying system pressure were carried out by Rizk and Lefebvre (1984). $G L R$ and relative exit velocities at the nozzle orifice were kept constant by variation of the gas and liquid mass flows. No information concerning the distance between measuring plane and nozzle orifice was given by the authors. With increasing system pressure from $p_{\text {sys }}=1.3-18.3$ bar, a decreasing Sauter mean diameter was detected, using two external mixing twin-fluid nozzles with different liquid orifice diameters. Risberg and Marklund (2009) conducted experiments using external mixing twin-fluid nozzles to atomize high viscosity liquids ( $\eta_{\text {liq }}=1-500 \mathrm{mPa} \cdot \mathrm{s}$ ). A HSC was used for qualitative investigation of large droplets and velocity. 
Table 2

Summary of investigations applying external mixing twin-fluid nozzles with $\eta_{\text {liq }}>1 \mathrm{mPa} \cdot \mathrm{s}$ at $p_{\text {sys }}>1$ bar.

\begin{tabular}{lllll}
\hline Author (year) & Measurement & $\eta_{\text {liq }}$ in $\mathrm{mPa} \cdot \mathrm{s}$ & $p_{\text {sys }}$ in bar & $(I) D_{a b} \sim p_{\text {sys }}^{x}$ \\
\hline Rizkalla and Lefebvre (1975) & LDS & $1-44$ & $1-8.5$ & $(I) D_{32} \sim p_{\text {sys }}^{-1}$ \\
Jasuja (1982) & LDS & $1.3-43.5$ & $1-14.2$ & $(I) D_{32} \sim p_{\text {sys }}^{-0.45}$ \\
Elkotb et al. (1982) & CGP & 33.5 & $1-8$ & $(I) D_{32} \sim p_{\text {sys }}^{-0.29}$ \\
Rizk and Lefebvre (1984) & LDS & $1.3-18.3$ & $1-7.7$ & $(I) D_{32} \sim p_{\text {sys }}^{-0.4}$ \\
Risberg and Marklund (2009) & HSC & $1-500$ & $1-10$ & $\mathrm{~N} / \mathrm{A}$ \\
Gullberg and Marklund (2012) & HSC & 25 & $1-5$ & $\mathrm{~N} / \mathrm{A}$ \\
Sänger (2018) & PDA, HSC & $100-400$ & $1-21$ & $\mathrm{M}:(I) D_{32} \sim p_{\text {sys }}^{-0.88}$ \\
& & & & $\mathrm{~F}:(I) D_{32} \sim p_{\text {sys }}^{-0.47}$ \\
\hline
\end{tabular}

The variation of system pressure was carried out at constant GLR. A dependency of system pressure on droplet size was not found. Continuing experiments were conducted by Gullberg and Marklund (2012), applying pyrolysis oil as low viscosity fuel. The liquid supply was realized via an annular gap of the external twinfluid nozzle. For increasing system pressure, gas velocities at the nozzle orifice and GLR were kept constant. To achieve these constant conditions while varying the system pressure, liquid and gas mass flow were adapted. An increase in primary jet length, fractions of larger droplets and droplet number density were detected with increasing system pressure by high-speed camera images. Further investigations on the atomization of high viscosity liquids at elevated system pressure $p_{\text {sys }}=21$ bar were performed by Sänger (2018). With increasing system pressure and constant gas velocity, a decreasing Sauter mean diameter was found. In order to achieve these constant conditions, GLR was increased from 0.4 at $p_{\text {sys }}=1$ bar up to 13.8 at $p_{\text {sys }}=21$ bar. Furthermore, it was reported that increasing the dynamic pressure of the gas phase $\rho_{\text {gas }} \cdot v_{\text {gas }}^{2}$ by either variation of gas density or gas velocity shows different results on droplet size.

Summing up the literature review, it must be stated that previous investigations cannot provide a comprehensive picture on local data for sprays under high system pressure conditions using high viscosity liquids. On the one hand, some studies mentioned show inconsistent results. On the other hand, the investigated parameters influencing the spray quality cannot be separated completely. Additional, previous investigation applying elevated system pressure were typically performed with one single nozzle, which results for high system pressures and constant gas velocity in high $G L R$ values. As an example for water measurements at increased system pressure, Mayer (1994) gives a good overview. These conditions are not relevant for an application like gasification, where low GLR is required (Fleck et al., 2018).

To get a better insight in the disintegration process of liquid jets applying twin-fluid nozzles and the initiating instabilities under high pressure conditions, more detailed data such as qualitative measurements of primary jet breakup and local highresolution measurements of drop size and velocity distributions are required. Due to this deficit of knowledge, the present study focuses on external mixing twin-fluid atomization of high viscosity liquids at elevated system pressure. As previous investigations of Jakobs (2015) and Sänger (2018) show, liquid velocity, gas velocity, and GLR are important parameters influencing the droplet size distribution of the spray. In order to investigate only the influence of system pressure on the atomization, these parameters were kept constant. To maintain constant boundary conditions, pressure adapted nozzles are used in the present study, i.e. nozzles with reduced cross section of the gas outlet are applied for every system pressure increment (see Table 3 ). With this approach, increasing system pressure results in constant $G L R$, momentum flow ratio, $R e_{\text {liq }}$, as well as gas velocity, while Weaero and $R e_{\text {gas }}$ increase with system pressure. Applying this set of nozzles is the first investigation of geometrical scaling to higher system pressure.
Table 3

Nozzle data (Nozzle 1 - 5) for each system pressure step.

\begin{tabular}{lllll}
\hline & $p_{\text {sys }}$ in bar & $D_{\text {liq }}$ in $\mathrm{mm}$ & $D_{\text {gas }}$ in $\mathrm{mm}$ & $A_{\text {gas }}$ in $\mathrm{mm}^{2}$ \\
\hline Nozzle 1 & 1 & 2.00 & 7.96 & 45.94 \\
Nozzle 2 & 2 & 2.00 & 5.84 & 22.97 \\
Nozzle 3 & 6 & 2.00 & 3.82 & 7.66 \\
Nozzle 4 & 11 & 2.00 & 3.19 & 4.18 \\
Nozzle 5 & 16 & 2.00 & 2.91 & 2.87 \\
\hline
\end{tabular}

\section{Experimental setup}

As described by Sänger et al. (2015), the experimental setup consists of the pressurized atomization test rig (PAT), a PDA, a shadow sizing measurement system, and a high-speed camera. For the experiments, 5 pressure adapted external mixing twin-fluid atomizers with similar geometry were used for the atomization of water and a glycerol/water - mixture. A scheme of the spray test rig PAT with exhaust air system and a horizontal cross-sectional view (A-A) is given in Fig. 1. The pressure chamber has an internal diameter of $300 \mathrm{~mm}$ and a total height of $3000 \mathrm{~mm}$. It is designed for operation at system pressures up to $p_{\text {sys }}=21$ bar. The external mixing twin-fluid atomizer is mounted on the axially $(z-$ direction) movable twin-fluid lance, which is fed by one of the two eccentric screw pumps with liquids featuring viscosities up to $\eta_{\text {liq }}=1000 \mathrm{mPa}$. s. Liquid mass flow can be controlled in the range of P1: $\dot{M}_{\text {liq }}=10-60 \mathrm{~kg} \cdot \mathrm{h}^{-1} / \mathrm{P} 2: \dot{M}_{\text {liq }}=60-200 \mathrm{~kg} \cdot \mathrm{h}^{-1}$ using different screw pumps. Liquid mass flow and density are measured by a Coriolis flow meter with an uncertainty of $<0.5 \%$ and controlled by FIRC (flow indication recording control) systems. The compressed air volume flow $\dot{V}_{\text {gas }}$ is detected by a turbine meter measuring in a range of $\dot{V}_{g a s}=0.85-25 \mathrm{~m}^{3} \cdot \mathrm{h}^{-1}$ with an uncertainty of $<0.5 \%$ and controlled by an FIRC system. A recalculation of volume to mass flow is done using the local measured gas temperature and pressure at the measurement turbine. System pressure control in the pressure chamber was made by a PIRC (pressure indication recording control) system and three corresponding valves after the gas/liquid separator. The liquid height in the separator tank was controlled by a LCA (level control alarm) system. To ensure well-defined nozzle inlet conditions, the liquid can be stirred and tempered in a range of $T=10{ }^{\circ} \mathrm{C}-50{ }^{\circ} \mathrm{C}$. The test rig is equipped with three glass windows (no inclusions or cords) that allow for optical access to the spray chamber and avoid any disturbances of the laser beam. Two optical ports are located at $\Phi_{R}=0^{\circ}$ and $70^{\circ}$ to enable Phase Doppler measurements in scattering mode with preferably highest intensity (first-order refraction) (Albrecht, 2003). The third optical port is positioned at $\Phi_{R}=180^{\circ}$ to allow for spray investigations in backlight mode with optical measurement systems. To ensure the protection from window deposits at the $\Phi_{R}=70^{\circ}$ window location, a wiper was used between the measurements, using compressed air for movement. A flow straightener (honeycomb structure) is located below the 


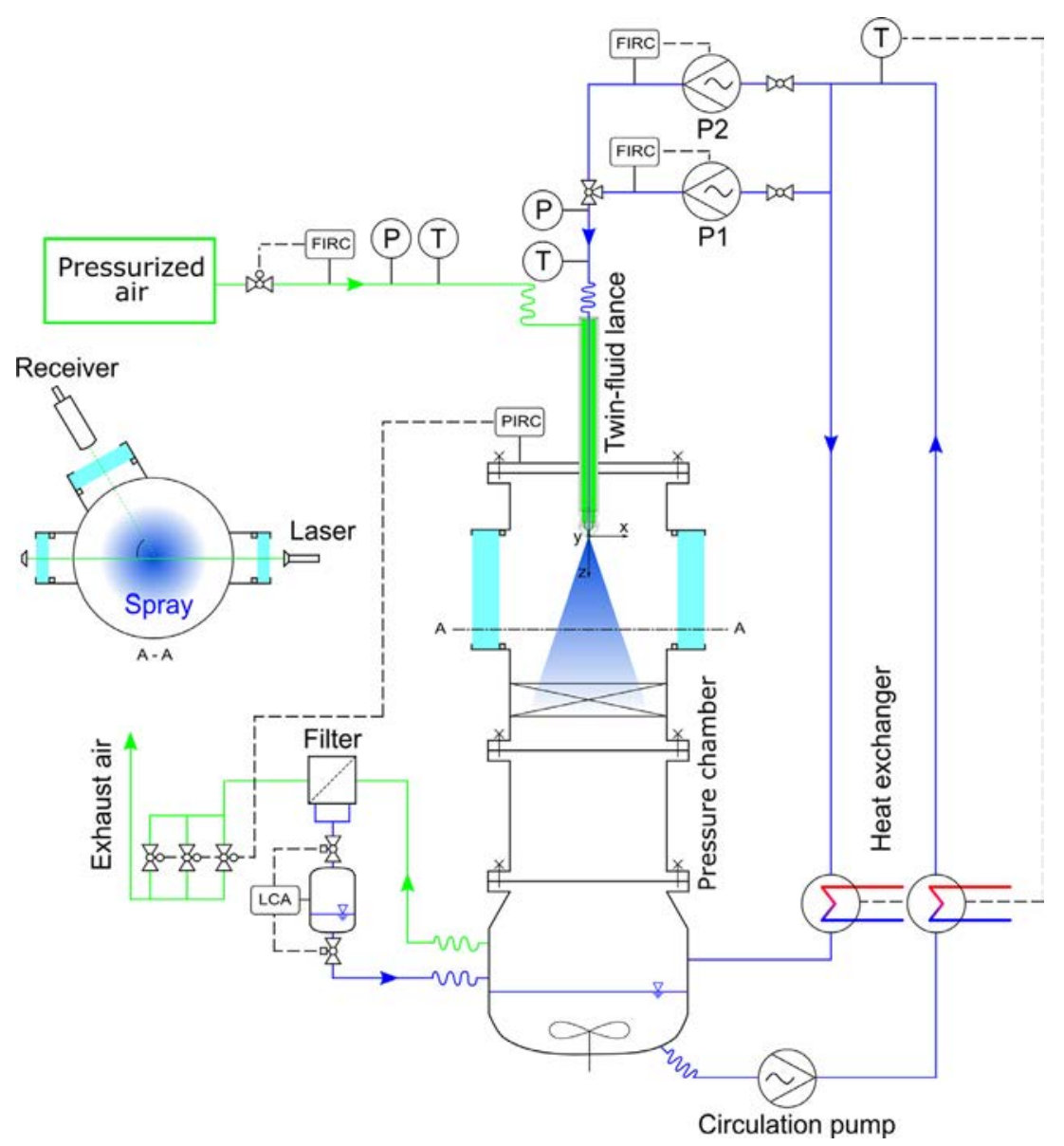

Fig. 1. Scheme of the experimental setup - Pressurized Atomization Test Rig (PAT).
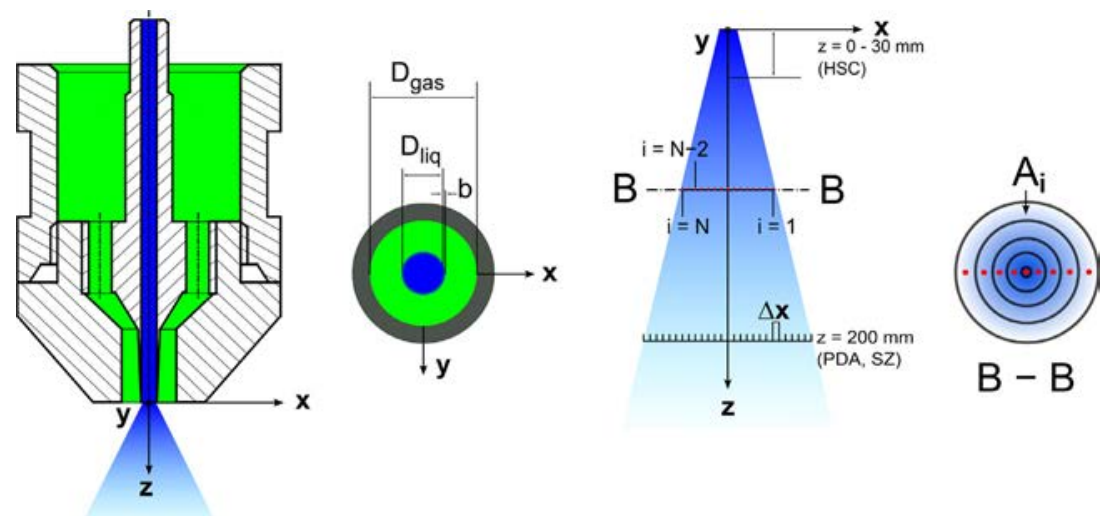

Fig. 2. Scheme of the external mixing twin-fluid nozzle.

measuring plane to avoid influences on the measurement due to recirculation of droplets into the region of interest.

All investigations were conducted with 5 pressure adapted external mixing twin-fluid nozzles as shown in Fig. 2. The liquid (blue) is supplied through a circular central tube $\left(D_{\text {liq }}=2 \mathrm{~mm}\right)$ at the nozzle axis. The liquid jet is surrounded by a coaxial gas stream (green). The nozzle has parallel flow channels to avoid disturbance of the liquid jet due to gas flow angle. In addition, the influence of the tube separating gas and liquid at the nozzle orifice was minimized by reduction of the wall thickness $b$ to $0.1 \mathrm{~mm}$. This configuration results in an undisturbed gas flow at the exit of the nozzle. For every system pressure, the related area of the annular gas orifice was adapted in order to achieve a constant gas velocity, GLR and mass flows, resulting in 5 different nozzles $1-5$, geometries given in Table 3. Those special nozzle configurations allow for solely varying the system pressure while keeping all other operating conditions ( $v_{g a s}, G L R, \dot{M}_{\text {liq }}$ ) constant. Exemplary follows for a system pressure of $p_{\text {sys }}=16 \mathrm{bar}$, a nozzle area ratio between nozzle 1 and nozzle 5 of $A_{g a s, 1} / A_{g a s, 5}=16$.

To investigate the influence of dynamic viscosity on the atomization process, water $\left(\eta_{\text {liq }}=1 \mathrm{mPa} \cdot \mathrm{s}\right)$ and a glycerol/water mixture $\left(\eta_{\text {liq }}=100 \mathrm{mPa} \cdot \mathrm{s}\right)$ were used. The physical properties of these Newtonian fluids were measured at $T=20^{\circ} \mathrm{C}$ and $p=1 \mathrm{bar}$, see Table 4. Dynamic viscosity was measured using a Searle-type (GFG, 1912) rheometer. Surface tension was determined using the du Noüy ring method (du Noüy, 1925) with a tensiometer, and 
Table 4

Physical properties of the investigated fluids at $T=20{ }^{\circ} \mathrm{C}$ and $p=1$ bar.

\begin{tabular}{lllll}
\hline & $\eta_{\text {liq }}$ in $\mathrm{mPa} \cdot \mathrm{s}$ & $\sigma$ in $\mathrm{N} \cdot \mathrm{m}^{-1}$ & $\rho_{\text {liq }}$ in $\mathrm{kg} \cdot \mathrm{m}^{-3}$ & Oh \\
\hline water & 1 & 0.0719 & 998 & 0.0026 \\
glycerol/water (84.3 wt. \%) & 100 & 0.0649 & 1220 & 0.2513 \\
\hline
\end{tabular}

liquid density by the weighing method. The influence of system pressure on both, dynamic viscosity (Mezger, 2006) and surface tension (Massoudi and King, 1974) is negligible for the investigated liquids.

A high-speed camera for qualitative investigation of the primary breakup process was applied in the nozzle nearfield. The camera features a frame rate of $3.6 \mathrm{kHz}$ operation at $1024 \times 1024$ pixel resolution and frame rates up to $500 \mathrm{kHz}$ at reduced resolution. A lens with focal length of $f_{H G}=105 \mathrm{~mm}$ was used to capture primary breakup morphologies. In this case, images have dimensions of $40.0 \times 30.0 \mathrm{~mm}^{2}$ or $40.0 \times 48.0 \mathrm{~mm}^{2}$ with a spatial resolution of $62.5 \mu \mathrm{m} \cdot \mathrm{pix}^{-1}$. The frame rate was set to $12 \mathrm{kHz}$ or $7.5 \mathrm{kHz}$, respectively. The images were captured by backlight illumination of the region of interest with a special lighting setup. An array of 9 high-power light-emitting diodes (LED) with total luminous flux of $9 \times 4500 \mathrm{~lm}$ was used. The position of each single LED within the LED array was optimized for best light spread. Due to the high intensity and the homogeneous distribution of the light, very short exposure times $\left(t_{\operatorname{Exp}} \sim 7 \mu \mathrm{s}\right)$ could be applied. This light setup allowed for a sharp representation of the droplets even in case of fast flow conditions. To guarantee for representative data of the liquid disintegration process, a set of 4000 high-speed images was recorded at every operating condition as well as a background reference image without liquid flow.

For observation of single droplets within the spray, a shadowsizer was employed and used (i) to optimize the PDA hardware settings (receiver mask), (ii) to determine the measuring plane where reliable measurements with the PDA system can be conducted (spherical droplets), (iii) to qualitatively confirm the tendencies measured by the PDA, and (iv) as a validation tool for the PDA system to remove deviations arising from the Gaussian beam effect (Araneo et al., 2002). The shadow sizing system consists of a CCD camera operating in backlight mode with a high efficiency diffuser that is powered by an Nd:YAG laser for illumination. The far-field microscope mounted on the camera allows for very small measuring volume of $2.8 \times 2.8 \times 0.8 \mathrm{~mm}^{3}$. The measuring volume, in combination with the camera resolution of 4 megapixels, results in a spatial resolution of $\sim 1.4 \mu \mathrm{m} /$ pixel and allows for the detection of all relevant droplet sizes. The accuracy of the shadow sizing system was checked using a calibration target with points of known size $(10 \mu \mathrm{m})$. The biggest measurement error was $<10 \mu \mathrm{m}$. Due to the fact that the shadow sizing system was used for qualitative investigations of large droplets only, the accuracy was considered as adequate. In order to obtain a reliable amount of droplets, a set of 1000 shadow images at an axial distance of $z=200 \mathrm{~mm}$ from the nozzle orifice was recorded and analyzed. Droplets without detectable contour were rejected.

Droplet size and velocity were measured with high spatial and temporal resolution within the spray cone by a fiber PDA system by Dantec Dynamics. For data collection, the PDA was operated in forward scattering arrangement and refraction mode ( $1^{\text {st }}$ order). The receiver was set to an off-axis angle of $\Phi_{R}=70^{\circ}$. In order to (i) get a well-defined detection volume dimension, (ii) to ensure for high data rates at dense spray conditions and (iii) to enable flux calculation, a slit with a physical length of $l_{S}=200 \mu \mathrm{m}$ was used, to reduce the length of the measurement volume. To guarantee for the detection of large droplets as expected by the atomization of high viscosity liquids and avoid sizing errors due to the Gaussian beam effect, lenses with a focal length of $1000 \mathrm{~mm}$ were used for
Table 5

Settings of the fiber PDA evaluated by the sensitivity analysis.

\begin{tabular}{lll}
\hline Parameters & Values & Unit \\
\hline Transmitter focal length $f_{T}$ & 1000 & $\mathrm{~mm}$ \\
Receiver focal length $f_{R}$ & 1000 & $\mathrm{~mm}$ \\
Beam expander ratio $E$ & 1 & - \\
Receiver slit width (physical) $l_{S}$ & 200 & $\mu \mathrm{m}$ \\
Laser wavelength $\lambda_{L}$ & 514.5 & $\mathrm{~nm}$ \\
Laser power (transmitter exit) & 25 & $\mathrm{~mW}$ \\
Off-axis angle $\Phi_{R}$ & 70 & $\circ$ \\
Frequency shift & 40 & $\mathrm{MHz}$ \\
\hline
\end{tabular}

both, transmitter $f_{T}$ and receiver $f_{R}$ (Araneo et al., 2002). In addition, the asymmetric Mask B was mounted in the receiver to eliminate possible measurement errors due to the Gaussian beam effect (trajectory effect). With this optical configuration, the PDA system allowed for detection of droplets with minimum size of $1 \mu \mathrm{m}$ and maximum size of $1307 \mu \mathrm{m}$ for water and $1330 \mu \mathrm{m}$ for the glycerol/water - mixture, depending on the refractive index of the liquid (Albrecht, 2003). To improve the PDA instrument settings towards small droplets (e.g. data rate and validation rate), the optimum PDA user settings were evaluated in advance by a sensitivity study (Kapulla and Najera, 2006). The PDA settings are given in Table 5 .

To enable drop size measurements at different positions within the spray cone, receiver and transmitter were mounted on a 3D traverse system, which guarantees for spatially operation with a reproducibility $<0.1 \mathrm{~mm}$. Data were obtained by moving the detection volume relatively to the nozzle position. The measurements were taken at several radial (traverse along $x$-axis) positions with a radial increment of $\Delta x=2 \mathrm{~mm}$. According to the orientation of the coordinate system as indicated in Fig. 2 and the alignment of the fringes of the laser beam couple $\left(\lambda_{L}=514.5 \mathrm{~nm}\right.$ - green), the axial droplet velocity component $v_{z}$ could be measured. To ensure a reliable database for every radial position during PDA measurements, the sample size was set to 50,000 droplets. Only for the outermost radial measuring position, the sample size of 50,000 droplets was not reached for all operating conditions. Nevertheless, at least 4000 droplets were detected at the boundary of the spray cone. The raw data from the manufacturer software were used to compute arithmetic means, statistical data, as well as additional information (i.e. mass flux and $I D_{32, m}$, etc.) using the toolbox SprayCAT (Sänger, 2018). For global characterization of the spray, the computation of a global characteristic diameter, i.e. mass-weighted integral Sauter mean diameter $I D_{32, m}$, was carried out by a weighted average, including all measurement positions of a radial profile at a fixed axial position $z$. The integral Sauter mean diameter $I D_{32, m}$ is calculated according to Eq. (4), based on the local volume mean diameter $D_{30, i}$ and local surface mean diameter $D_{20, i}$. These diameters are weighted by local mass flux $\dot{m}_{i}$ and the annulus area $A_{i}$ (see Fig. 2), corresponding to the measurement position $i$ along the radial axis $x_{1} \leq x_{i} \leq x_{N}$ with $N$ measurement positions. The outermost point $x_{N}$ for each operating condition is defined by a minimum of the ratio of data rate $f_{i}$ divided by maximum data rate $f_{\max }$ along the radial profile, which was set to 0.1 .

$I D_{32, m}=\frac{\sum_{i=1}^{N} D_{30, i}^{3} \dot{m}_{i} A_{i}}{\sum_{i=1}^{N} D_{20, i}^{2} \dot{m}_{i} A_{i}}$ 
Table 6

Operating conditions of the experiments.

\begin{tabular}{llll}
\hline$p_{\text {sys }}$ in bar & $\dot{M}_{\text {gas }}$ in $\mathrm{kg} \cdot \mathrm{h}^{-1}$ & $v_{\text {gas }}$ in $\mathrm{m} \cdot \mathrm{s}^{-1}$ & $G L R$ \\
\hline $1 / 2 / 6 / 11 / 16$ & $12 / 16 / 20$ & $60 / 80 / 100$ & $0.6 / 0.8 / 1.0$ \\
\hline
\end{tabular}

Further information concerning computation of global size distribution and drop size moments can be obtained from DIN SPEC 91325 as well as from Albrecht (2003). The mass flux $\dot{m}_{i}$ was calculated from PDA data according to Albrecht (2003) using the toolbox SprayCAT. All PDA measurements were conducted at an axial distance of $z=200 \mathrm{~mm}$ from the nozzle orifice and repeated at least 3 times. For each operating condition and nozzle, rotational symmetry of the spray cone was proven, taking a full radial profile in a first set of experiments. After rotational symmetry was proven, the following repetition measurements were performed taking half profiles from the spray edge to the center at $x=0 \mathrm{~mm}$. The results of those sets of experiments were afterwards mirrored to get full profiles. Therefore, all radial Sauter mean diameter distributions are shown as mirrored profiles at $x=0 \mathrm{~mm}$ and the plotted and mirrored data points are shown as open symbols.

\section{Results and discussion}

In order to investigate the influence of (i) gas velocity $v_{\text {gas }}$, (ii) system pressure $p_{\text {sys }}$ and (iii) dynamic viscosity $\eta_{\text {liq }}$ on resulting droplet size and primary breakup at constant liquid mass flow of $\dot{M}_{l i q}=20 \mathrm{~kg} \cdot \mathrm{h}^{-1}$, pressure adapted nozzles were applied as a scaling approach. This results for every system pressure step in constant operating conditions, named $\dot{M}_{\text {gas }}, \dot{M}_{\text {liq }}, G L R$, $v_{\text {gas }}$. Additional, to examine the effect of gas velocity, three different gas mass flow rates $\dot{M}_{g a s}$ were chosen for the five system pressure settings $p_{\text {sys }}$. The operating conditions for all measurements are presented in Table 6. The atomization agent in all experiments was pressurized air at $T=20{ }^{\circ} \mathrm{C}$. The supplied liquids were also tempered at $T=20^{\circ} \mathrm{C}$.

\subsection{Influence of gas velocity, system pressure and dynamic viscosity} on droplet velocity

In the following section the investigation on the influence of gas velocity on local axial droplet velocity are discussed for dif- ferent system pressure and dynamic viscosity of the liquid. The measurements were performed at an axial distance of $z=200 \mathrm{~mm}$ downstream the nozzle exit, applying a PDA system. Exemplarily results for glycerol/water - mixture $\left(\eta_{\text {liq }}=100 \mathrm{mPa} \cdot \mathrm{s}\right)$ at $v_{\text {gas }}=$ $60 \mathrm{~m} \cdot \mathrm{s}^{-1}$ (Fig. 3a) and a comparison of water $\left(\eta_{\text {liq }}=1 \mathrm{mPa} \cdot \mathrm{s}\right)$ and glycerol/water - mixture $\left(\eta_{\text {liq }}=100 \mathrm{mPa} \cdot \mathrm{s}\right)$ for $v_{\text {gas }}=100 \mathrm{~m}$. $\mathrm{s}^{-1}$ (Fig. 3b) are shown.

Fig. 3 shows the number-averaged axial droplet velocity $v_{d r}, z$, mean for gas velocities of $v_{\text {gas }}=60 \mathrm{~m} \cdot \mathrm{s}^{-1}$ (Fig. 3a) and $v_{\text {gas }}=$ $100 \mathrm{~m} \cdot \mathrm{s}^{-1}$ (Fig. $3 \mathrm{~b}$ ) for system pressure of $p_{\text {sys }}=1-16 \mathrm{bar}, z=$ $200 \mathrm{~mm}$ downstream the nozzle orifice. Additionally, Fig. 3b shows the influence of liquid viscosity on $v_{d r, z \text {, mean }}\left(\eta_{\text {liq }}=1 \mathrm{mPa} \cdot \mathrm{s} /\right.$ left and $\eta_{\text {liq }}=100 \mathrm{mPa} \cdot \mathrm{s} /$ right). The typical Gaussian shaped radial profile of external mixing twin-fluid atomizers was detected. All velocity profiles show rotational symmetry with deviations smaller than $\Delta v_{d r, z}=1 \mathrm{~m} \cdot \mathrm{s}^{-1}$ between left and corresponding right side of the centerline. In addition, the error bars plotted in Fig. 3 indicate the repeatability of the experiments. It was detected that droplets of a size range between $1-5 \mu \mathrm{m}$ at $z=200 \mathrm{~mm}$ show velocity deviations smaller than $\Delta v_{d r, z}=0.8 \mathrm{~m} \cdot \mathrm{s}^{-1}$ towards the number-averaged droplet velocity of all droplets shown in Fig. 3, i.e. slip between droplet and gas phase can be neglected, secondary breakup of droplets is finished, thus $z=200 \mathrm{~mm}$ is a reasonable measuring position to characterize droplet size of the spray.

For increasing gas velocity at the nozzle orifice, higher axial droplet velocities are detected, see Fig. $3 \mathrm{a}$ at $v_{\text {gas }}=60 \mathrm{~m} \cdot \mathrm{s}^{-1} \mathrm{com}-$ pared to Fig. $3 \mathrm{~b}$ at $v_{\text {gas }}=100 \mathrm{~m} \cdot \mathrm{s}^{-1}$. Applying pressure adapted nozzles at increasing system pressure, the axial droplet velocity over the whole spray width decreases for all gas velocities and liquid viscosities. This can be explained by the free jet theory and Eq. (5) for calculation of the gas free jet, which is based on the assuming of conservation of momentum (Schlichting et al., 2006).

$$
\frac{v(z)}{v_{\text {gas }}}=6.37 \cdot \frac{d_{e q}}{z} \cdot \sqrt{\frac{\rho_{0}}{\rho}}
$$

Here, $v_{\text {gas }}$ is the gas velocity at the nozzle orifice, $v(z)$ is the gas velocity at distance $z$ on the spray axis, $\rho_{0}$ is the gas density at the nozzle orifice, $\rho$ is the density of the ambient gas phase and $d_{e q}$ is the equivalent diameter of the gas exit of the nozzle. With increasing system pressure the gas outlet area $A_{\text {gas }}$ of the nozzle is reduced due to the pressure adapted scaling approach (see Table 3 ).
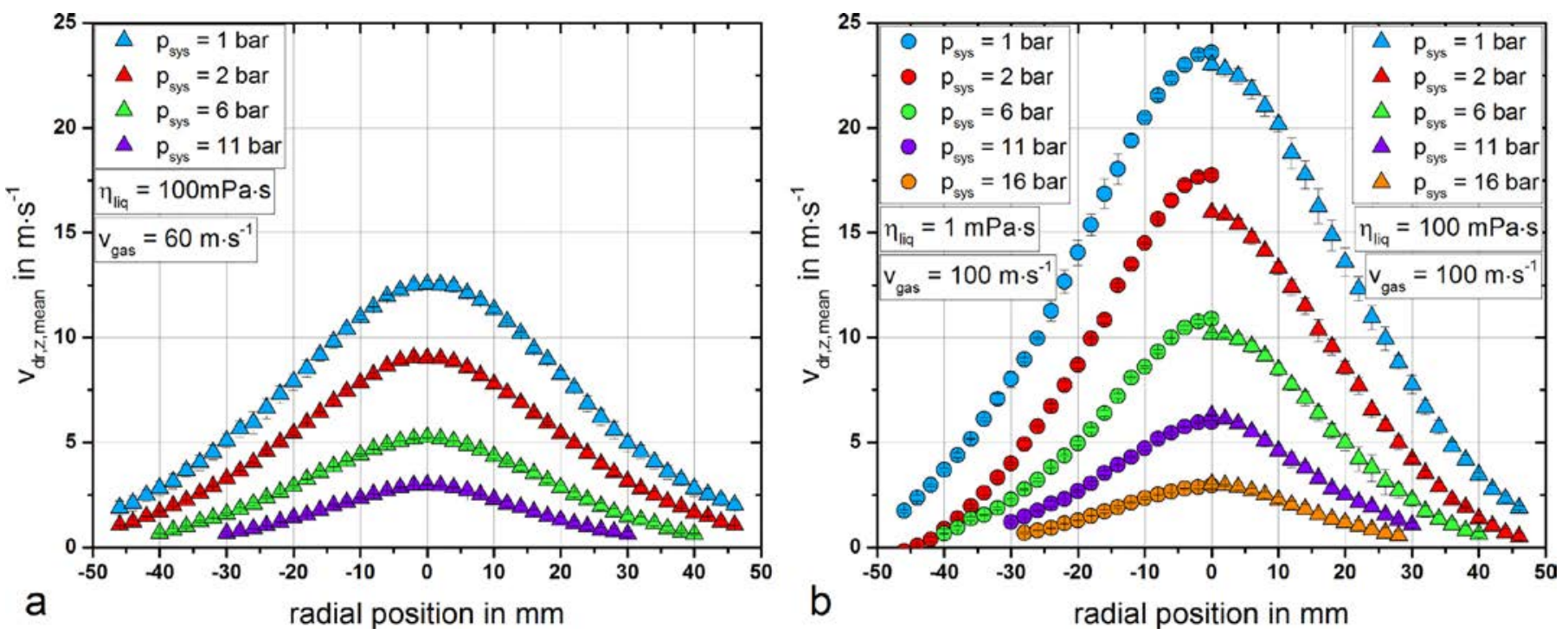

Fig. 3. Radial measurements of the number-averaged axial droplet velocity distributions as a function of system pressure a) for glycerol/water - mixture $\left(\eta_{\text {liq }}=100 \mathrm{mPa} \cdot \mathrm{s}\right)$ at $v_{\text {gas }}=60 \mathrm{~m} \cdot \mathrm{s}^{-1}$ and $\left.\mathrm{b}\right)$ a comparison of water $\left(\eta_{\text {liq }}=1 \mathrm{mPa} \cdot \mathrm{s}\right)$ and glycerol $/$ water - mixture $\left(\eta_{\text {liq }}=100 \mathrm{mPa} \cdot \mathrm{s}\right)$ at $v_{\text {gas }}=100 \mathrm{~m} \cdot \mathrm{s}^{-1}$. 


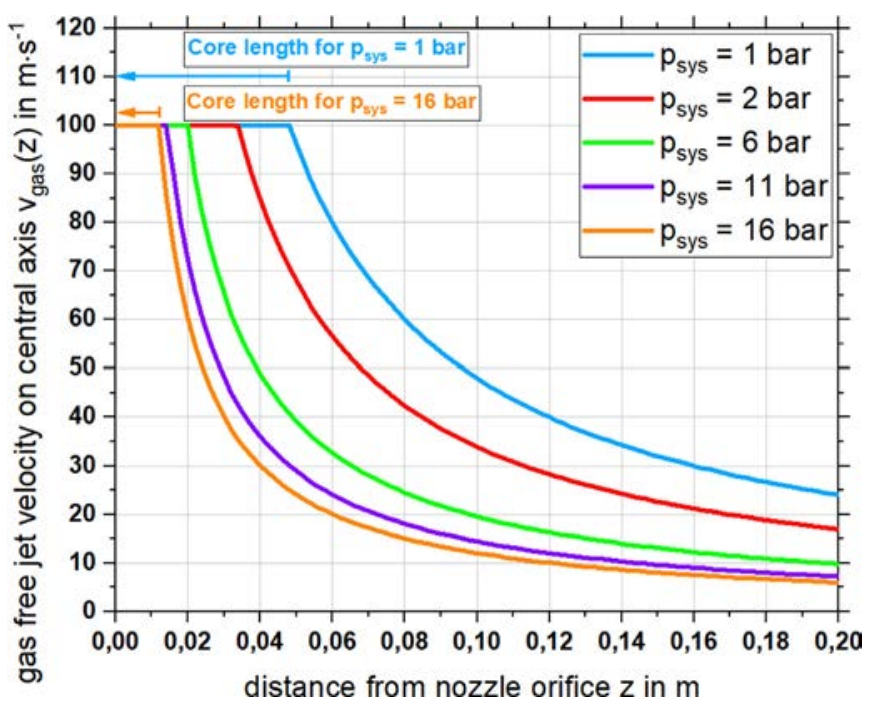

Fig. 4. Calculation of the gas free jet velocity on central axis for $v_{\text {gas }}=100 \mathrm{~m} \cdot \mathrm{s}^{-1}$ applying pressure adapted nozzles at $p_{s y s}=1-16$ bar. The core length of constant gas velocity is marked as arrows for $p_{\text {sys }}=1$ bar and $p_{\text {sys }}=16$ bar.

A decrease in the gas orifice area leads to smaller equivalent diameter of the gas exit $d_{e q}$. The ratio $\rho_{0}$ over $\rho$ does not depend on system pressure, due to the small and therefore negligible difference between ambient gas and atomizing air density. Smaller $d_{e q}$ values lead, according to Eq. (5), towards lower values of the gas velocity $v(z)$ at same distance $z$, while the exiting gas velocity at the nozzle orifice remains constant. Physically, this deceleration of gas velocity downstream the nozzle can be explained by the entrainment of ambient gas into the atomization gas jet emerging from the nozzle. As system pressure is increased and pressure adapted nozzles are applied, the entrainment increases, due to the decreasing equivalent diameter $d_{e q}$. This change in nozzle geometry affects the gas jet core length, which is characterized by constant gas velocity, as shown exemplarily for $v_{\text {gas }}=100 \mathrm{~m} \cdot \mathrm{s}^{-1}$ in Fig. 4 (Schlichting et al., 2006).

For increasing system pressure while applying the pressure adapted scaling approach, a decrease in the gas velocity $v(z)$ for every distance $z$ is calculated. This results in a shorter core length, where the slow liquid phase is exposed to the fast atomization gas jet. As a consequence, this decreased core length leads to a decrease in gas-liquid-interaction and therefore to droplets with lower velocities.

3.2. Influence of gas velocity, system pressure and dynamic viscosity on Sauter mean diameter

For quantitative investigation, the influence of gas velocity, system pressure, and dynamic viscosity on spray quality was detected by a PDA system using $D_{32}$ as a characterization criterion. Sauter mean diameter profiles across the whole spray cone at an axial distance of $z=200 \mathrm{~mm}$ downstream the nozzle orifice for water $\left(\eta_{\text {liq }}=1 \mathrm{mPa} \cdot \mathrm{s}\right)$ and glycerol/water - mixture $\left(\eta_{\text {liq }}=100 \mathrm{mPa} \cdot \mathrm{s}\right)$ were performed. The results for the high viscosity liquid $\left(\eta_{\text {liq }}=\right.$ $100 \mathrm{mPa} \cdot \mathrm{s}$ ) are presented in Fig. 5 as radial profiles.

\subsubsection{Influence of gas velocity on Sauter mean diameter}

Fig. 5 shows exemplarily the radial distribution of $D_{32}$ for system pressure of $p_{\text {sys }}=1-16$ bar at $v_{\text {gas }}=60 \mathrm{~m} \cdot \mathrm{s}^{-1}$ (Fig. 5a) and $v_{\text {gas }}=100 \mathrm{~m} \cdot \mathrm{s}^{-1}$ (Fig. $5 \mathrm{~b}$ ) for the glycerol/water mixture with viscosity of $\eta_{\text {liq }}=100 \mathrm{mPa}$. $\mathrm{s}$. An increase of gas velocity leads to a decrease of Sauter mean diameter for each system pressure. The influence of gas velocity on the resulting $D_{32}$ is more pronounced for system pressures $p_{\text {sys }}>6$ bar. The various shapes of the $D_{32}$ profiles are discussed in detail in the following sections.

\subsubsection{Influence of system pressure on Sauter mean diameter}

For $v_{\text {gas }}=60 \mathrm{~m} \cdot \mathrm{s}^{-1}$ increasing system pressure up to $p_{\text {sys }}=$ 6 bar results in a slight reduction of the Sauter mean diameter, a further increase of the system pressure $p_{\text {sys }}>6$ bar shows larger droplet sizes, especially near the spray axis. Similar dependencies were found for $v_{\text {gas }}=100 \mathrm{~m} \cdot \mathrm{s}^{-1}$, where the influence of system pressure for $p_{s y s}<6$ bar is less pronounced compared to $v_{\text {gas }}=60 \mathrm{~m} \cdot \mathrm{s}^{-1}$.

\subsubsection{Shape of the Sauter mean diameter profiles}

Fig. 5 clearly shows a change in shape of the Sauter mean diameter profiles with increasing system pressure and gas velocity. For $v_{\text {gas }}=60 \mathrm{~m} \cdot \mathrm{s}^{-1}$ the flat $D_{32}$ profiles for $p_{\text {sys }}<6$ bar turn into a profile with a pronounced peak at the spray axis for
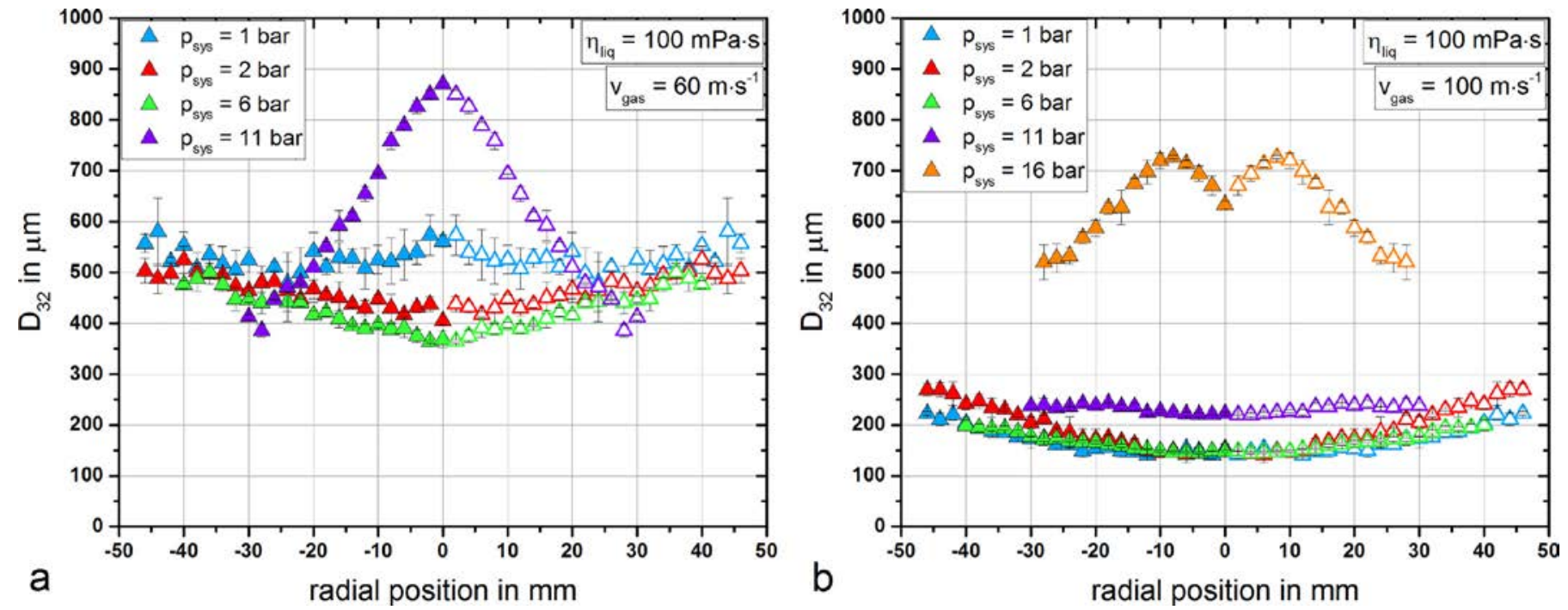

Fig. 5. Radial distribution of Sauter mean diameter at $z=200 \mathrm{~mm}$ below the nozzle orifice as a function of system pressure for glycerol/water - mixture $\left(\eta_{\text {liq }}=100 \mathrm{mPa} \cdot \mathrm{s}\right)$ at a) $v_{\text {gas }}=60 \mathrm{~m} \cdot \mathrm{s}^{-1}$ and b) $v_{\text {gas }}=100 \mathrm{~m} \cdot \mathrm{s}^{-1}$ (open symbols denote mirrored positions). 


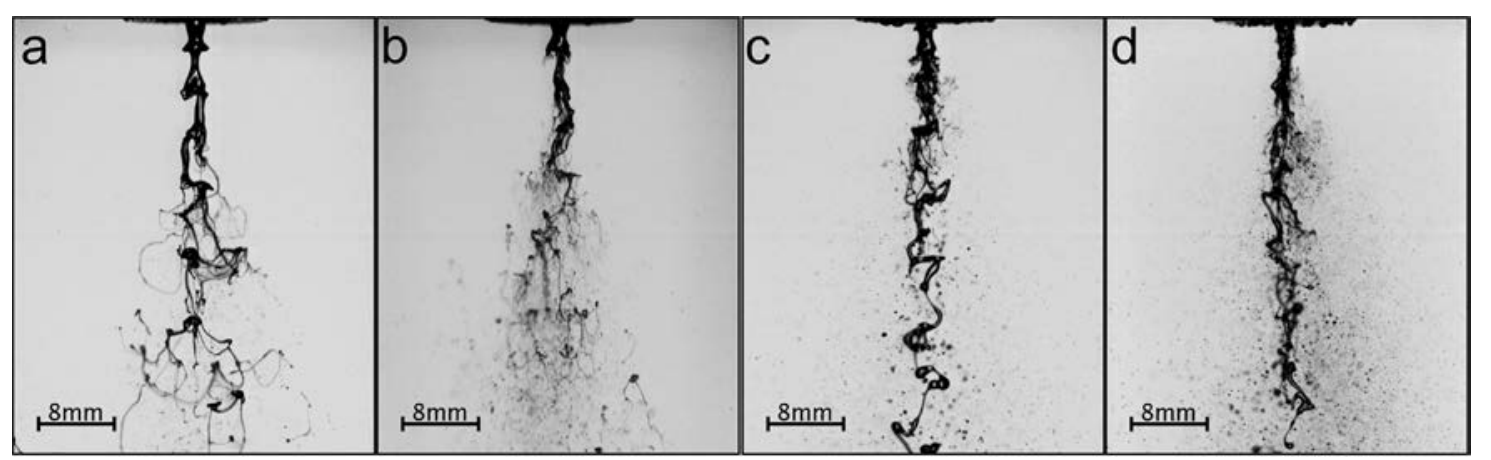

Fig. 6. High-speed camera images of primary jet breakup for glycerol/water - mixture $\left(\eta_{\text {liq }}=100 \mathrm{mPa} \cdot \mathrm{s}\right)$ at a) $p_{\text {sys }}=1 \mathrm{bar}, v_{\text {gas }}=60 \mathrm{~m} \cdot \mathrm{s}^{-1}$, b) $p_{\text {sys }}=1 \mathrm{bar}, v_{\text {gas }}=100 \mathrm{~m}$. $\mathrm{s}^{-1}$, c) $p_{\text {sys }}=11$ bar, $v_{\text {gas }}=60 \mathrm{~m} \cdot \mathrm{s}^{-1}$ and d) $p_{\text {sys }}=16$ bar, $v_{\text {gas }}=100 \mathrm{~m} \cdot \mathrm{s}^{-1}$.

$p_{\text {sys }}=11$ bar. For $v_{\text {gas }}=100 \mathrm{~m} \cdot \mathrm{s}^{-1}$ the uniform profile is maintained up to $p_{\text {sys }}=11$ bar, but a further system pressure increase to $p_{s y s}=16$ bar leads to a significant increase in drop size with a pronounced M-shape radial profile. However, a M-shaped profile is observed by the measurement, due to the PDA measurement limit mentioned in the description above, see also Albrecht (2003). Without this measurement limit, the radial profile would also be inverse V-shaped. In order to understand the physical effects responsible for these findings, additional high-speed camera images were taken. Fig. 6 shows primary jet break-up for different process conditions, indicating that the shape of the profiles results from different breakup morphologies of the primary jet. In Fig. 6 only the glycerol/water - mixture with $\eta_{\text {liq }}=100 \mathrm{mPa} \cdot \mathrm{s}$ is shown in sense of simplicity, referring to $R e_{\text {liq }}=35$ and $O h=0.2513$. Furthermore, breakup morphologies are classified and compared towards the findings of Lasheras and Hopfinger (2000), noting that the nozzle geometry was similar, but with different dimensions and liquid properties.

Fig. 6a $\left(p_{\text {sys }}=1\right.$ bar, $\left.v_{\text {gas }}=60 \mathrm{~m} \cdot \mathrm{s}^{-1}, W e_{\text {aero }}=128\right)$ shows a membrane type breakup; small droplets are formed by the disintegration of membranes and are partly accelerated in radial direction away from the spray axis, while larger droplets, originated from membrane rims, stay in the center of the spray. This results in the W-shaped radial distribution of $D_{32}$ as shown in Fig. (5)a. For this atomization conditions (We $\left.e_{a e r o}, O h\right)$ the membrane type breakup was also proposed by Lasheras and Hopfinger (2000) and Zhao et al. (2012).

Fig. $6 \mathrm{~b}\left(p_{\text {sys }}=1 \mathrm{bar}, v_{\text {gas }}=100 \mathrm{~m} \cdot \mathrm{s}^{-1}, W e_{\text {aero }}=361\right)$ shows a fiber type breakup situation. As a consequence of the higher relative velocity in the spray center compared to the boundary of the spray, liquid fragments in the center are disintegrated into smaller droplets. Liquid fragments at the spray boundary form droplets without further disintegration due to the low shear rate, leading to a U-shape distribution according to Fig. 5b. For this operating conditions Zhao et al. (2012) still estimate a membrane type breakup, whereas Lasheras and Hopfinger (2000) predict a transition region between membrane and fiber breakup, which is in good accordance to the prevailing breakup.

In Fig. 6c $\left(p_{\text {sys }}=11\right.$ bar, $\left.v_{\text {gas }}=60 \mathrm{~m} \cdot \mathrm{s}^{-1}, W e_{\text {aero }}=1395\right)$ the aerodynamic force of the gas jet is not sufficient to disintegrate the whole liquid jet. This leads to the peel off of some fibers from the primary jet close to the nozzle orifice, whereas the center of the jet is not affected. Finally, the liquid core breaks up into large droplets by Kelvin-Helmholtz and Rayleigh-Plateau instabilities. This explains the inverse V-shape of the radial $D_{32}$ profile with maximum on the spray axis shown in Fig. 5a. For this operating conditions, Zhao et al. (2012) as well as Lasheras and Hopfinger (2000) predict a fiber type breakup, due to the high aerody- namic We number calculated with values at the nozzle orifice. Due to the increased deceleration of the gas velocity with increased system pressure and the applied pressure scaling of the nozzles, near the nozzle orifice a fiber type breakup can be detected, while the liquid core remains constant and disintegrates according to the non-axisymmetric Rayleigh type breakup. This effect stays for system pressures $p_{\text {sys }}>6$ bar in contrast to previous regime classifications.

The spray shown in Fig. $6 \mathrm{~d}\left(p_{\text {sys }}=16\right.$ bar, $v_{\text {gas }}=100 \mathrm{~m}$. $\mathrm{s}^{-1}, W e_{\text {aero }}=5882$ ) corresponds to the M-shaped $D_{32}$-profile in Fig. 5b. Due to the partly prevailing non-axisymmetric Rayleightype breakup of the primary jet, droplet diameters $d>D_{\text {liq }}$ are found near the spray center shown in Fig. 6d. From shadowsizer images the maximum detected droplet diameter on the centerline of the spray was $d_{\max }=3072 \mu \mathrm{m}$. This leads to the conclusion that the local Sauter mean diameter would actually even be higher than predicted by the PDA measurements and form a Gaussian shaped profile. The minimum of Sauter mean diameter in the spray center is only detected, due to some smaller detectable droplets formed near the nozzle orifice and the exceeding droplet size over the measurement limit of the PDA system. Regarding regime classification the prediction of breakup morphology from both authors Lasheras and Hopfinger (2000) and Zhao et al. (2012) show same deviations as for Fig. 6c, due to the incomplete breakup detected at even higher aerodynamic We number.

Concluding the regime classification, for increase of $v_{\text {gas }}$, results were in good accordance to the literature. Applying the pressure adapted nozzles at increased system pressure, results at $p_{\text {sys }}>6$ bar were not comparable with both authors Lasheras and Hopfinger (2000) and Zhao et al. (2012). One possible reason could be the fact that commonly used dimensionless numbers (We, Oh) do not include all relevant nozzle geometry parameters.

\subsubsection{Influence of dynamic viscosity on sauter mean diameter}

The influence of dynamic viscosity is discussed in detail on mass-weighted integral Sauter mean diameter, see in section below. Experimental data on Sauter mean diameter profiles, not given in this paper, show that increase in dynamic viscosity leads to the formation of membranes and ligaments due to the damping effect, as described by Zhao et al. (2012). Those ligaments disintegrate into large droplets which result in an increase of droplet size for all operating conditions. This effect is also shown by HSC images as shown in Fig. 11.

\subsection{Influence of gas velocity, system pressure and dynamic viscosity on mass-weighted integral sauter mean diameter}

In order to compare the spray quality at different operating conditions for both viscosities, local drop sizes measured at 

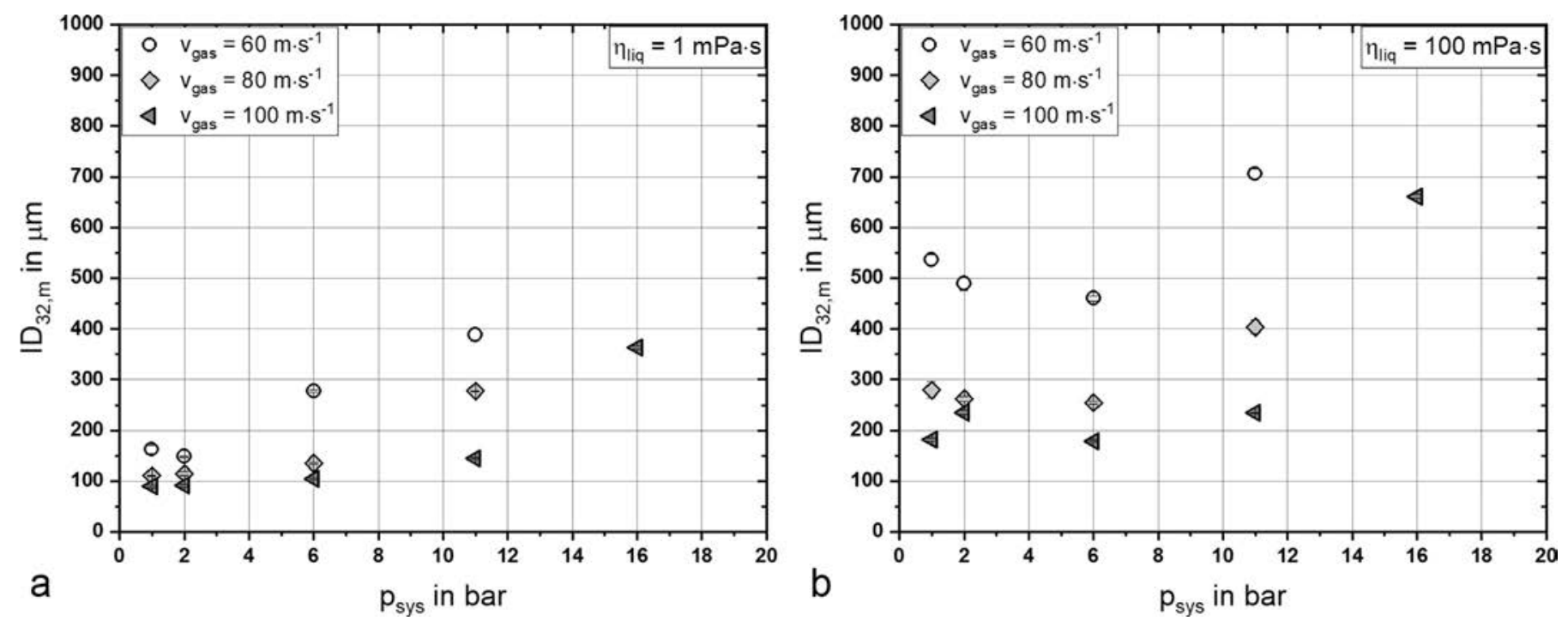

Fig. 7. Mass-weighted integral Sauter mean diameter as a function of system pressure $p_{\text {sys }}$ and gas velocity $v_{\text {gas }}$ for a) water $\left(\eta_{\text {liq }}=1 \mathrm{mPa} \cdot \mathrm{s}\right)$ and $\left.\mathrm{b}\right)$ glycerol/water $-\mathrm{mixture}$ $\left(\eta_{\text {liq }}=100 \mathrm{mPa} \cdot \mathrm{s}\right)$.

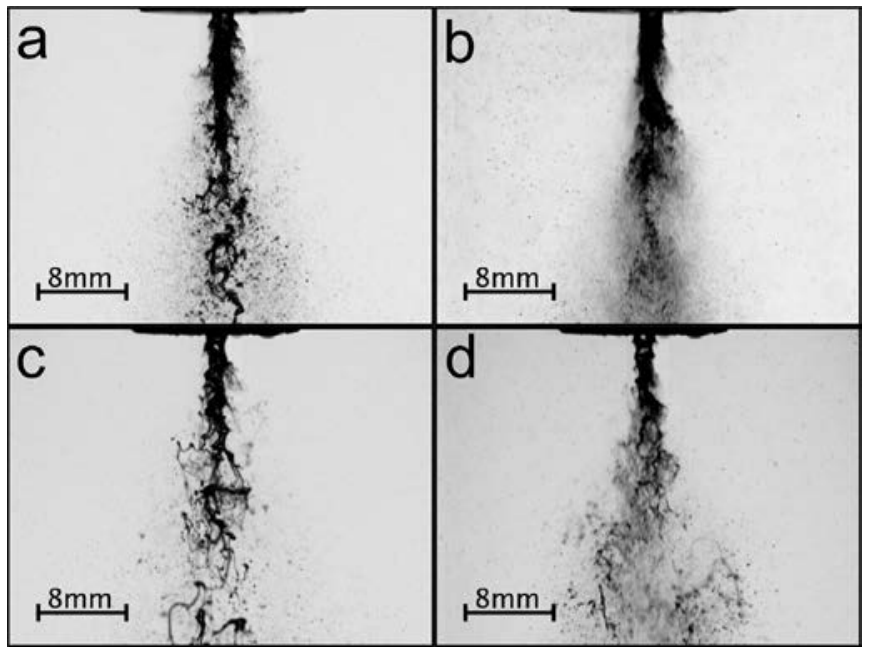

Fig. 8. High-speed camera images of primary jet breakup for water $\left(\eta_{\text {liq }}=\right.$ $1 \mathrm{mPa} \cdot \mathrm{s}$ ) at a) $p_{\text {sys }}=6 \mathrm{bar}, v_{\text {gas }}=60 \mathrm{~m} \cdot \mathrm{s}^{-1}$ and b) $p_{\text {sys }}=6 \mathrm{bar}, v_{\text {gas }}=100 \mathrm{~m} \cdot \mathrm{s}^{-1}$ and glycerol/water - mixture $\left(\eta_{\text {liq }}=100 \mathrm{mPa} \cdot \mathrm{s}\right)$ at c) $p_{\text {sys }}=6 \mathrm{bar}, v_{\text {gas }}=60 \mathrm{~m} \cdot \mathrm{s}^{-1}$ and d) $p_{\text {sys }}=6$ bar, $v_{\text {gas }}=100 \mathrm{~m} \cdot \mathrm{s}^{-1}$.

$z=200 \mathrm{~mm}$ were used to calculate the $I D_{32, m}$ according to Eq. (4). For different gas velocities and system pressures, the values of $I D_{32, m}$ are plotted as function of system pressure in Fig. 7. Fig. 7a shows the $I D_{32, m}$ for water with $\eta_{\text {liq }}=1 \mathrm{mPa} \cdot \mathrm{s}$ and Fig. $7 \mathrm{~b}$ for glycerol/water - mixture with $\eta_{l i q}=100 \mathrm{mPa} \cdot \mathrm{s}$, respectively.

\subsubsection{Influence of gas velocity on mass-weighted integral Sauter mean diameter}

A decrease of $I D_{32, \mathrm{~m}}$ with increasing gas velocity can be detected for all system pressures and liquid viscosities, see Fig. 7 . For higher system pressure $p_{s y s} \geq 6$ bar and higher liquid viscosity, the influence of gas velocity is even more pronounced. This effect is confirmed by the high-speed camera images of primary jet breakup shown in Fig. 8. Large ligaments are found in the nozzle nearfield for $v_{\text {gas }}=60 \mathrm{~m} \cdot \mathrm{s}^{-1}$, see Fig. 8a and Fig. $8 \mathrm{c}$, whereas only few small liquid fragments are detected for $v_{\text {gas }}=100 \mathrm{~m} \cdot \mathrm{s}^{-1}$ in Fig. $8 \mathrm{~b}$ and Fig. 8d. In addition, a reduction of the primary ligament length can be seen with increased gas velocity.
3.3.2. Influence of system pressure on mass-weighted integral Sauter mean diameter

With increasing system pressure, a minimum in the $I D_{32, m}$ can be detected for the glycerol/water - mixture at $p_{\text {sys }}=6$ bar for all gas velocities, for water this effect is less pronounced at $p_{\text {sys }}=$ 2 bar (see Fig. 7). The high-speed camera images in Fig. 9, where primary jet breakup is shown at $v_{\text {gas }}=100 \mathrm{~m} \cdot \mathrm{s}^{-1}$ for water at system pressure of $p_{\text {sys }}=1$ bar (Fig. 9a), 6 bar (Fig. 9b) and 16 bar (Fig. 9c) and for glycerol/water at system pressure of $p_{\text {sys }}=1$ bar (Fig. 9d), 6 bar (Fig. 9e) and 16 bar (Fig. 9f) confirm these findings.

One possible explanation of this effect is the difference in the dynamic pressure of the gas jet $\rho_{\text {gas }} \cdot v_{\text {gas }}^{2}$, which describes the aerodynamic force on the liquid jet according to Wegas (Lasheras and Hopfinger, 2000; Sänger, 2018; Kumar and Sahu, 2018; Xiao et al., 2014). The gas velocity in the jet is reduced due to the entrainment of ambient gas (free jet behaviour, see Eq. (5)). This entrainment shows a higher effect on the deceleration of the gas phase, when increasing system pressure and applying pressure adapted nozzles, see Fig. 4. In order to quantify this assumption, the measured velocity of droplets in the size range from $1-5 \mu \mathrm{m}$ was used to describe the local $v_{\text {gas }}$ at $z=200 \mathrm{~mm}$ (Tropea et al., 2007). The derived radial distribution of the dynamic pressure of the gas jet is shown in Fig. 10 for glycerol/water - mixture at $p_{\text {sys }}=1,6$ and 16 bar and $v_{\text {gas }}=100 \mathrm{~m} \cdot \mathrm{s}^{-1}$. For constant gas velocity at the nozzle exit, a maximum of the dynamic pressure of the gas phase can be detected for $p_{\text {sys }}=6$ bar on the spray axis. This maximum could lead to the formation of smaller droplets. For significantly increasing system pressure at $p_{s y s}>6$ bar, the dynamic pressure of the gas phase is decreasing, see Fig. 10. The maximum of the dynamic pressure of the gas phase can be explained by opposite effects:

- With increasing system pressure, the density of the gas phase increases. This leads to increased aerodynamic forces between liquid and gas phase as well as higher dynamic pressure of the gas jet resulting in smaller droplets. According to this, the correlations listed in Table 2 show a decrease of droplet size with increasing system pressure.

- Applying the pressure adapted nozzle design at elevated system pressure an increased deceleration of the atomization jet velocity is detected which is described by Eq. (5). As described previously, the increased deceleration of the gas phase is caused by the reduction of $A_{g a s}\left(d_{e q}\right)$. As the reduction of the gas phase 


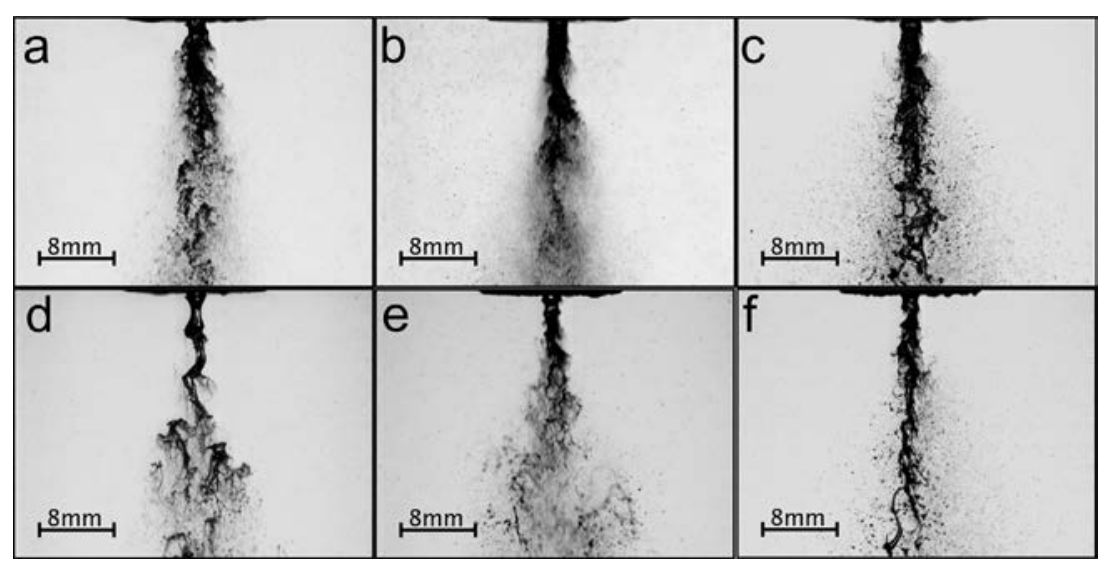

Fig. 9. High-speed camera images of primary jet breakup at $v_{\text {gas }}=100 \mathrm{~m} \cdot \mathrm{s}^{-1}$ for water $\left(\eta_{\text {liq }}=1 \mathrm{mPa} \cdot \mathrm{s}\right)$ at a) $p_{\text {sys }}=1$ bar, b) $p_{\text {sys }}=6$ bar and $\left.\mathrm{c}\right) p_{\text {sys }}=16$ bar and for the glycerol/water - mixture $\left(\eta_{\text {liq }}=100 \mathrm{mPa} \cdot \mathrm{s}\right)$ at d) $\left.p_{\text {sys }}=1 \mathrm{bar}, \mathrm{e}\right) p_{\text {sys }}=6$ bar and f) $p_{\text {sys }}=16$ bar.

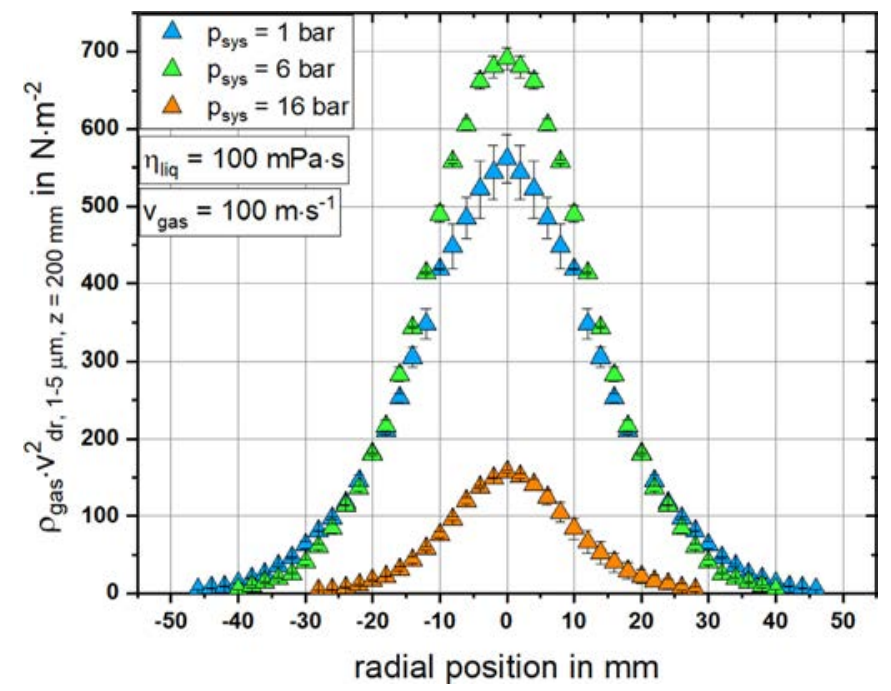

Fig. 10. Influence of system pressure $p_{s y s}$ on the radial distribution of dynamic pressure of the gas jet (calculated out of the velocity of droplets with a size of $1-5 \mu \mathrm{m}$ at $z=200 \mathrm{~mm})$ for glycerol/water - mixture $\left(\eta_{\text {liq }}=100 \mathrm{mPa} \cdot \mathrm{s}\right)$ and $v_{\text {gas }}=100 \mathrm{~m} \cdot \mathrm{s}^{-1}$.

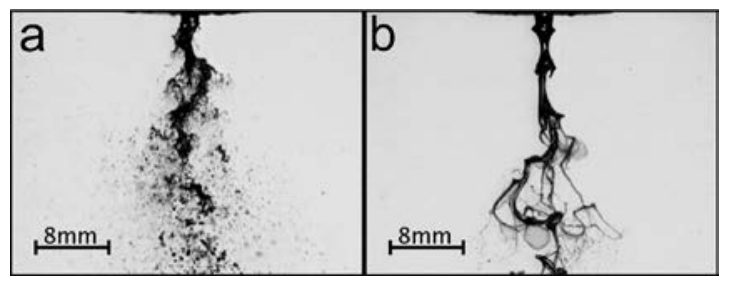

Fig. 11. High-speed camera images of primary jet breakup at $p_{\text {sys }}=1$ bar and $v_{\text {gas }}=$ $60 \mathrm{~m} \cdot \mathrm{s}^{-1}$ for a) water $\left(\eta_{\text {liq }}=1 \mathrm{mPa} \cdot \mathrm{s}\right)$ and $\left.\mathrm{b}\right)$ glycerol/water - mixture $\left(\eta_{\text {liq }}=\right.$ $100 \mathrm{mPa} \cdot \mathrm{s})$.

velocity along the spray axis (see Fig. 4) shows little effect at $p_{\text {sys }}<6$ bar, for $p_{\text {sys }}>6$ bar the reduction of gas phase velocity outside the nozzle affects the dynamic pressure of the gas jet and therefore the primary breakup, leading to a significant increase of droplet size.

Due to the fact, that for the calculation of the dynamic pressure of the gas jet the gas velocity is weighted by the power of 2 , whereas gas density is weighted by the power of 1 , for the given operating conditions in Fig. 10 the maximum is found at $p_{\text {sys }}=6$ bar.

\subsubsection{Influence of dynamic viscosity on mass-weighted integral Sauter mean diameter}

For increasing dynamic viscosity, bigger droplets were detected independent of system pressure and gas velocity, see Fig. 7. This is also confirmed by high-speed camera images of the primary jet breakup as exemplarily shown for $p_{s y s}=1$ bar and $v_{\text {gas }}=60 \mathrm{~m}$. $\mathrm{s}^{-1}$ in Fig. 11. For higher system pressure $p_{\text {sys }}>6$ bar and $v_{\text {gas }}=$ $100 \mathrm{~m} \cdot \mathrm{s}^{-1}$, the droplet size increases with a steeper gradient at higher dynamic viscosity, see Fig. 7a and Fig. 7b. This can be explained by enhancing effects of the damping liquid and the low dynamic pressure of the gas jet and is in good accordance to the correlations shown in Table 1.

\section{Conclusion}

In the present study, the influence of system pressure and liquid viscosity on jet breakup and spray quality $\left(D_{32}, I D_{32, m}\right)$ for two Newtonian liquids ( 1 and $100 \mathrm{mPa} \cdot \mathrm{s}$ ) was investigated. Nozzle geometry was adapted to the system pressure in order to keep all other operating conditions ( $v_{\text {gas }}, G L R, \dot{M}_{g a s}$ ) constant, independent of system pressure. Liquid mass flow was kept constant at $20 \mathrm{~kg}$. $\mathrm{h}^{-1}$ while the gas velocity was varied between 60 and $100 \mathrm{~m} \cdot \mathrm{s}^{-1}$, which resulted in a variation of GLR from 0.6 to 1.0. High-speed camera images were classified according to the breakup regimes defined by Chigier and Faragó (1992) and discussed with regard to local measurements of droplet size. The following conclusions can be drawn:

1. Increasing the gas velocity always leaded to a decrease in droplet size independent of system pressure and liquid viscosity.

2. Increasing the liquid viscosity always leaded to an increase in droplet size independent of system pressure and gas velocity.

3. Increasing the system pressure while applying pressure adapted for constant gas velocity leads to a minimum in droplet size:

(a) For the given nozzle geometry and operating conditions, the droplet size minimum is detected at 6 bar for $100 \mathrm{mPa} \cdot \mathrm{s}$, $60-100 \mathrm{~m} \cdot \mathrm{s}^{-1}$ and 2 bar for $1 \mathrm{mPa} \cdot \mathrm{s}, 60 \mathrm{~m} \cdot \mathrm{s}^{-1}$. A further increase of the system pressure above 6 bar leaded to an exponential increase of droplet size.

(b) High-speed camera images revealed a change in primary jet breakup morphology from fiber type towards a mixture of fiber type and non-axisymmetric Rayleigh type breakup at high system pressures. This effect was observed for both liquid viscosities ( 1 and $100 \mathrm{mPa} \cdot \mathrm{s}$ ) and seems responsible for the trend observed. 
(c) One possible explanation for this effect is the maximum of the dynamic pressure of the gas jet. With higher system pressure, gas density increases, while the smaller gas orifice area due to the pressure adapted nozzles approachindicates an increased deceleration of the gas phase according to the free jet theory. Overlapping of both effects results in an increase of dynamic pressure of the gas phase for low system pressure towards a maximum, followed by a decrease for high system pressure.

\section{Declaration of Competing Interest}

The authors declare that they have no known competing financial interests or personal relationships that could have appeared to influence the work reported in this paper.

\section{CRediT authorship contribution statement}

Simon Wachter: Conceptualization, Validation, Formal analysis, Investigation, Visualization, Writing - original draft. Tobias Jakobs: Conceptualization, Supervision, Writing - review \& editing. Thomas Kolb: Conceptualization, Supervision, Writing - review \& editing.

\section{Acknowledgements}

The authors gratefully acknowledge the financial support by the Helmholtz Association of German Research Centers (HGF), within the research program Energy Efficiency, Materials and Resources (EMR). The present work contributes to the Helmholtz Virtual Institute for Gasification Technology - HVIGasTech (VH-VI-429). http: //www.hvigastech.org/.

\section{References}

Albrecht, H.-E., 2003. Laser Doppler and Phase Doppler Measurement Techniques. Springer, Berlin and, New York.

Aliseda, A., Hopfinger, E.J., Lasheras, J.C., Kremer, D.M., Berchielli, A., Connolly, E.K. 2008. Atomization of viscous and non-Newtonian liquids by a coaxial, highspeed gas jet. Experiments and droplet size modeling. Int. J. Multiphase Flow 34 (2), 161-175. doi:10.1016/j.ijmultiphaseflow.2007.09.003.

Araneo, L., Damaschke, N., Tropea, C., 2002. Measurement and Prediction of the Gaussian Beam Effect in the PDA. Springer 189-208.

Chigier, N., Faragó, Z., 1992. Morphological classification of disintegration of round liquid jets in a coaxial air stream. Atom. Sprays 2 (2), 137-153.

du Noüy, P.L., 1925. An interfacial tensiometer for universal use. J. Gen. Physiol. 7 (5), 625.

Elkotb, M., El-Sayed Mahdy, M., Montaser, M., 1982. Investigation of External Mixing Air Blast Atomizers.

Fleck, S., Santo, U., Hotz, C., Jakobs, T., Eckel, G., Mancini, M., Weber, R., Kolb, T., 2018. Entrained flow gasification part 1: gasification of glycol in an atmospheric-pressure experimental rig. Fuel 217, 306-319.
GFG, S., 1912. Simple viscometer for very viscous liquids. In: Proceedings of the Cambridge Philosophical Society, Mathematical and Physical Sciences.

Gullberg, M., Marklund, M., 2012. Spray characterization of twin fluid external mixing atomization of pyrolysis oil. Atom. Sprays 22 (11), 897-919. doi:10.1615/ AtomizSpr.2013006240.

Haidn, O.J., Habiballah, M., 2003. Research on high pressure cryogenic combustion. Aerosp. Sci. Technol. 7 (6), 473-491. doi:10.1016/S1270-9638(03)00052-X

Hede, P.D., Bach, P., Jensen, A.D., 2008. Two-fluid spray atomisation and pneumatic nozzles for fluid bed coating/agglomeration purposes: a review. Chem. Eng. Sci. 63 (14), 3821-3842. doi:10.1016/j.ces.2008.04.014

Jakobs, 2015. Einfluss des Reaktordrucks auf die Spraygüte Außenmischender Zweistoffdüsen. KIT, Karlsruhe Dissertation.

Jakobs, T., Djordjevic, N., Fleck, S., Zarzalis, N., Kolb, T., 2012. Influence of Ambient Pressure on Twin Fluid Atomization R\&D Work for High Pressure Entrained Flow Gasification.

Jasuja, A.K., 1982. Plain-jet airblast atomization of alternative liquid petroleum fuels under high ambient air pressure conditions. Am. Soc. Mech. Eng. (3).

Kapulla, R., Najera, S.B., 2006. Operation conditions of a phase doppler anemometer: droplet size measurements with laser beam power, photomultiplier voltage, signal gain and signal-to-noise ratio as parameters. Meas. Sci. Technol. 17 (1), 221-227. doi:10.1088/0957-0233/17/1/034.

Kumar, A., Sahu, S., 2018. Liquid jet breakup unsteadiness in a coaxial air-blast atomizer. International Journal of Spray and Combustion Dynamics 10 (3), 211 230. doi:10.1177/1756827718760905. 175682771876090

Lefebvre, A.H., 1998. Gas Turbine Combustion. CRC Press.

Li, L.K.B., Dressler, D.M., Green, S.I., Davy, M.H., 2009. Experiments on air-blast atomization of viscoelastic liquids, part 1: quiescent conditions. Atom. Sprays 19 (2), 157-190

Lasheras, J.C., Hopfinger, E.J., 2000. Liquid jet instability and atomization in a coaxial gas stream. Annu. Rev. Fluid Mech. 32 (1), 275-308.

Lorenzetto, G.E., Lefebvre, A.H., 1977. Measurements of drop size on a plain-jet airblast atomizer. AIAA J. 15 (7), 1006-1010.

Marmottant, P., Villermaux, E., 2004. On spray formation. J. Fluid Mech. (498) 73-111.

Massoudi, R., King, A.D., 1974. Effect of pressure on the surface tension of water adsorption of low molecular weight gases on water at 25.deg. J. Phys. Chem. 78 (22), 2262-2266. doi:10.1021/j100615a017.

Mayer, W., 1994. Coaxial atomization of a round liquid jet in a high speed gas stream: a phenomenological study. Exp Fluids 16 (6), 401-410.

Mezger, T.G., 2006. The Rheology Handbook: For Users of Rotational and Oscillatory Rheometers. Vincentz Network GmbH \& Co KG.

Risberg, M., Marklund, M., 2009. Visualization of gas assisted atomization of black liquor and syrup water mixtures at elevated ambient pressures. Atom. Sprays 19 (10), 957-967.

Rizk, N., Lefebvre, A., 1984. Spray characteristics of plain-jet airblast atomizers. ASME 634 (106).

Rizkalla, A., Lefebvre, A.H., 1975. The influence of air and liquid properties on airblast atomization. J. Fluids Eng. 97 (3), 316-320.

Sänger, 2018. Zerstäubung Hochviskoser Fluide bei Variierendem Systemdruck Grundlagenforschung zur Hochdruck-Flugstromvergasung. Karlsruher Institut für Technologie (KIT), Karlsruhe Dissertation.

Sänger, A., Jakobs, T., Djordjevic, N., Kolb, T., 2015. Experimental investigation on the influence of ambient pressure on twin-fluid atomization of liquids with various viscosities. In: International Conference for Liquid Atomization and Spray System (ICLASS), Tainan, Taiwan, Aug, pp. 23-27.

Schlichting, H., Gersten, K., Krause, E. 2006. Grenzschicht-Theorie: Mit 22 Tabellen, 10., überarbeitete auflage Springer-Verlag, Berlin, Heidelberg doi:10.1007| 3-540-32985-4.

Tropea, C., Yarin, A.L., Foss, J.F., 2007. Handbook of Experimental Fluid Mechnics, first ed Springer Berlin Heidelberg.

Walzel, P., 1990. Zerstäuben von Flüssigkeiten. Chem. Ing. Tech. 62 (12), 983-994. doi:10.1002/cite.330621203

Xiao, F., Dianat, M., McGuirk, J.J., 2014. Les of turbulent liquid jet primary breakup in turbulent coaxial air flow. Int. J. Multiphase Flow 60, 103-118. doi:10.1016/j. ijmultiphaseflow.2013.11.013.

Zhao, H., Liu, H.-F., Xu, J.-L., Li, W.-F., Cheng, W., 2012. Breakup and atomization of a round coal water slurry jet by an annular air jet. Chem. Eng. Sci. 78, 63-74. doi:10.1016/j.ces.2012.05.007. 
Karlsruher Institut für Technologie

\section{Repository KITopen}

Dies ist ein Postprint/begutachtetes Manuskript.

Empfohlene Zitierung:

Wachter, S.; Jakobs, T.; Kolb, T.

Experimental investigation on the influence of system pressure on resulting spray quality and jet breakup applying pressure adapted twin-fluid nozzles.

2020. International journal of multiphase flow, 125.

doi: $\underline{10.5445 / I R / 1000105083}$

Zitierung der Originalveröffentlichung:

Wachter, S.; Jakobs, T.; Kolb, T.

Experimental investigation on the influence of system pressure on resulting spray quality and jet breakup applying pressure adapted twin-fluid nozzles.

2020. International journal of multiphase flow, 125, Article no: 103189.

doi:10.1016/j.ijmultiphaseflow.2019.103189 